\title{
GLOBAL PATTERNS IN SOIL BACTERIAL COMMUNITY COMPOSITION ACROSS A CONTINENTAL SCALE
}

\author{
http://dx.doi.org/10.4322/apa.2014.025 \\ Leandro Nascimento Lemos ${ }^{1}$, Afnan Khalil Ahmad Suleiman¹, \\ Antônio Batista Pereira ${ }^{1}$, Luiz Fernando Wurdig Roesch ${ }^{1, *}$ \\ 'Universidade Federal do Pampa - UNIPAMPA, Campus São Gabriel, São Gabriel, RS, Brazil \\ *e-mail: luizroesch@unipampa.edu.br
}

Abstract: Although patterns of variation regarding macroorganisms have been studied extensively, the links between microbial biogeography and the environmental factors that shape microbial communities are largely unexplored. Here we tested the Baas Becking hypothesis for microbial community distribution by analysing the soil bacterial community from the Brazilian Pampa and King George Island, Antarctica. The genetic community structure was assessed by automated ribosomal intergenic spacer analysis (ARISA fingerprint). Bacterial patterns were quantified by using hierarchical clustering and by the detection of the shared taxonomic unities between the environments. Geographical patterns in bacterial community structure were detected by broad-spectrum (between samples from different geographic locations) and specific-spectrum (within samples from different geographic locations), suggesting that microbial communities exhibit biogeographic patterns at different scales and that, at least, some taxonomic unities have a wide distribution. These preliminary results support the idea that "everything is everywhere, but, the environment selects".

Key words: Antarctica, Brazilian Pampa, biodiversity, culture-independent technique

\section{Introduction}

Biogeography is the study of the distribution of biodiversity over space and time, which describes general trends and location of populations and their attributes into a geographic context (Lomolino et al., 2006). Although patterns of variation with respect to macroorganisms have been studied extensively, the links between microbial biogeography and the environmental factors (e.g. vegetation cover, latitude, climate, temperature, and animal abundance) that shape microbial communities are largely unexplored. Some research studies support the idea that microbial communities differ in different places and the extent of this spatial variation is due to contemporary environmental factors and historical contingencies. This is the so-called Baas Becking hypothesis for microbial community distribution: "everything is everywhere, but, the environment selects" (de Wit \& Bouvier, 2006; Martiny et al., 2006). It implies that different contemporary environments maintain distinctive microbial assemblages but also implies that microorganisms have such enormous dispersal capabilities that they rapidly erase the effects of past evolutionary and ecological events. This is especially important for monitoring and better understanding the impact of global changes on the Antarctic terrestrial environment.

Our understanding of the spatial distribution patterns of microbial diversity is narrow because most studies are limited to local scales (for example, Chow et al., 2002; Hackl et al., 2004; Lamarche et al., 2007; Yergeau et al., 2010). In this work we tested the Baas Becking hypothesis by analysing the bacterial community across a broad continental scale. Soils from two sites across the southern 
hemisphere were chosen and samples included from two continents, Antarctica (King George Island) and the Americas (Rio Grande do Sul, Brazil).

\section{Material and Methods}

Samples were collected from three distinct environments across a broad geographical scale and included a wellpreserved gallery forest and anthropogenic grassland under severe degradation in the Brazilian Pampa and soil samples from ice-free areas located in the northwest side of the Keller Peninsula at 1,300 m from the Brazilian Antarctic Base at King George Island, Antarctica (Table 1).

Bacterial community composition was assessed by ARISA, a culture-independent technique for constructing bacterial community fingerprints based on the length heterogeneity of the intergenic transcribed spacer region of bacterial rRNA operons (Fisher \& Triplett, 1999). A set of 21 soil samples (Table 1) were collected from the top $10 \mathrm{~cm}$ of the surface and microbial DNA was extracted directly from the soil samples using the MoBio Power Soil extraction kit (MoBio, Carlsbad, CA, USA). PCR was performed with the GoTaq PCR core system (Promega, Madison, WI, USA). The mixtures contained $5 \mathrm{ml}$ of PCR buffer, $200 \mathrm{mM}$ dNTPs, $100 \mathrm{mM}$ of each primer, $2.5 \mathrm{U}$ of Taq polymerase and approximately $100 \mathrm{ng}$ of DNA template in a final volume of $50 \mu \mathrm{L}$. The primers used were S-D-Bact- 1522-b-S-20 and L-D-Bact-132-a-A-18 (Ranjard et al., 2001). Reaction mixtures were held at $94{ }^{\circ} \mathrm{C}$ for 3 minutes, followed by 30 cycles of amplification at $94^{\circ} \mathrm{C}$ for 45 seconds, $55^{\circ} \mathrm{C}$ for 1 minutes and $72{ }^{\circ} \mathrm{C}$ for 2 minutes and a final extension of $72{ }^{\circ} \mathrm{C}$ for 7 minutes.
The amplification product fragments were then resolved on a $2 \%$ agarose gel. Size standards were also resolved in separate wells to estimate the size of each PCR product. The Bray-Curtis similarity index was calculated to assess the degree of similarity among the samples and produce a similarity matrix. The resulting matrices with pairwise similarities were used to group samples that represented similar bacterial community composition. Hierarchical clustering was calculated by using complete linkage algorithm and the results were represented by a dendrogram with the $\mathrm{x}$ axis representing the full set of samples and the $y$ axis defining a similarity level at which two samples were considered to have fused. All data analyses for the ARISA bands were conducted using the software PRIMER 6 version 6.1.9 (PRIMER-E Ltd, Luton, UK). The overall fraction of taxonomic unities shared between the microbiome detected in the Brazilian Pampa and the Antarctica was determined by assessing the presence/absence of specific ARISA bands.

\section{Results}

The first step in assessing habitat distributions for bacteria was to determine the degree of similarity among samples and group them based on the communities composition. The dendrogram depicting this cluster analysis is shown in Figure 1a. Bacterial communities were more similar within the Brazilian Pampa and Antarctica sites and least similar between both environments. Nevertheless the samples presented a high overall variability clustering at low similarity even within the samples from the same geographical location. Cluster III made up of five samples collected from Antarctica was fused at $30 \%$ similarity while Cluster I made up of most of the samples from the Brazilian

Table 1. Origin of the soil sample, location, elevation and number of samples collected in each environment analyzed.

\begin{tabular}{|c|c|c|c|}
\hline Origin of soil & Latitude/longitude & Elevation & Number of samples \\
\hline Gallery forest, Brazilian Pampa & $\begin{array}{l}30^{\circ} 24^{\prime} 09.3^{\prime \prime} \mathrm{S} \\
53^{\circ} 52^{\prime} 59.1^{\prime \prime} \mathrm{W}\end{array}$ & $140 \mathrm{~m}$ & 10 \\
\hline Grassland, Brazilian Pampa & $\begin{array}{l}30^{\circ} 24^{\prime} 08.9^{\prime \prime} \mathrm{S} \\
50^{\circ} 53^{\prime} 05.9^{\prime \prime} \mathrm{W}\end{array}$ & $230 \mathrm{~m}$ & 5 \\
\hline King George Island, Antarctica & $\begin{array}{l}62^{\circ} 03^{\prime} 51.1^{\prime \prime} \mathrm{S} \\
58^{\circ} 24^{\prime} 47.5^{\prime \prime} \mathrm{W}\end{array}$ & $32 \mathrm{~m}$ & 6 \\
\hline
\end{tabular}




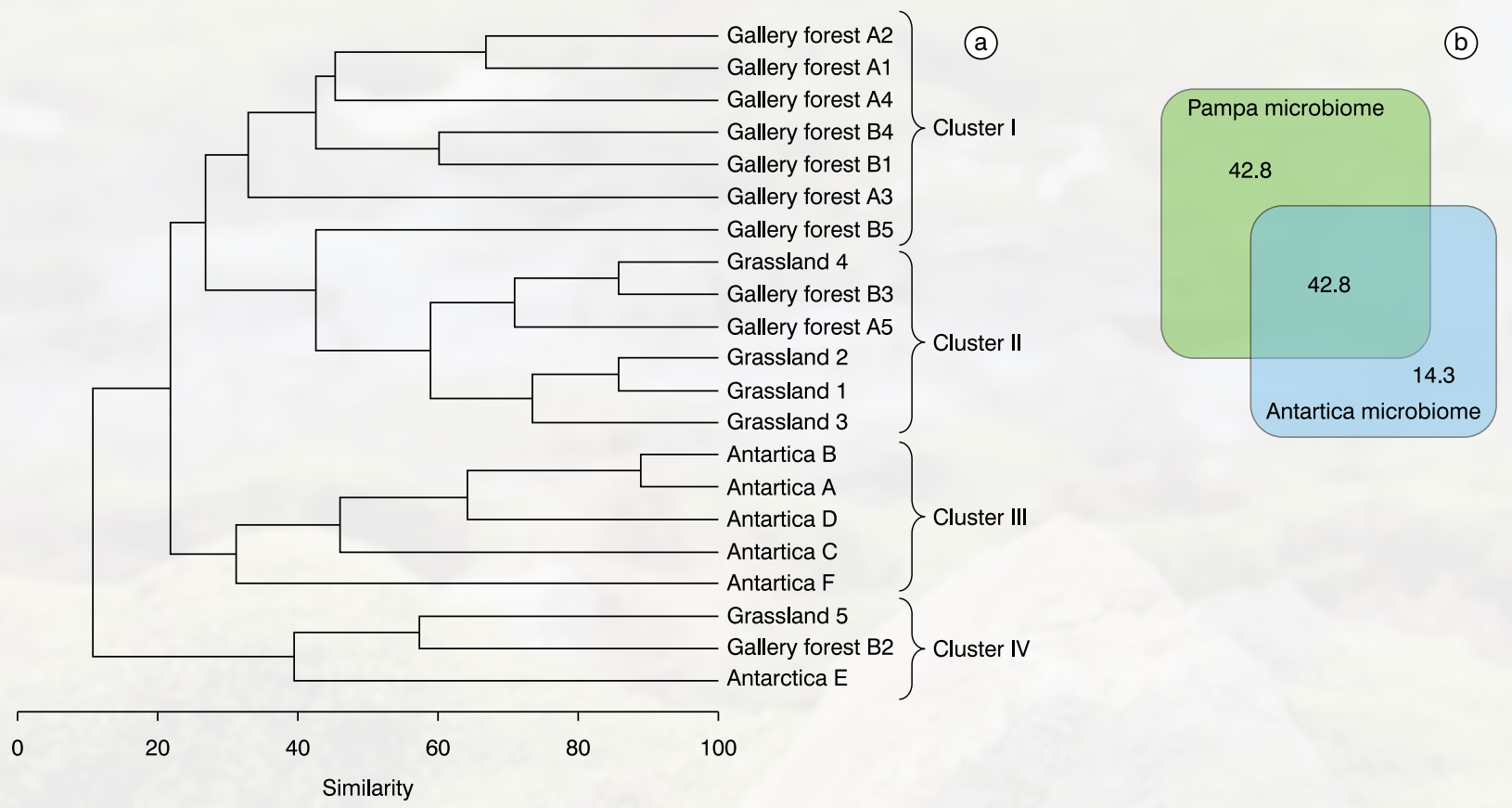

Figure 1. a) Dendrogram illustrating the arrangement of the clusters based on the presence/absence of ARISA fragments using DNA samples from gallery forest and grassland soil samples from the Brazilian Pampa and soil samples from defrosting areas in the King George Island, Antarctica. b) Venn diagram showing overall overlap of taxonomic unities between two microbial communities Antarctica and the Brazilian Pampa. The numbers are expressed in percentage of taxonomic unities.

Pampa was fused at 25\% similarity. This result indicates a large spatial variability even between samples from similar environments. On the other hand, the dendrogram also shows a single cluster (Cluster IV) with $40 \%$ similarity among samples made up of representatives from each environment analysed denoting that there is a link between bacterial community composition.

The cluster analysis encouraged us to examine bacterial diversity more directly using the ARISA bands to detect taxonomic unities that were in common between the Brazilian Pampa and the Antarctica samples. The results of this analysis are summarized in a Venn diagram, which presents the fraction of taxonomic unities that are unique and shared between both environments (Figure 1b). Several taxonomic unities were distinct to habitats (14.3 and 42.8\% found only in Antarctica and the Brazilian Pampa respectively), while $42.8 \%$ of the taxonomic unities appeared to be shared between environments.

\section{Discussion}

Since microbial composition affects ecosystem processes (McGrady-Steed et al., 1997), the motivation for understanding microbial biogeography extends beyond drawing and interpreting a map of microbial diversity. Even under similar environmental conditions, microbial communities from different environments might function differently. Therefore, a better understanding of microbial biogeography is essential to predict such effects (Martiny et al., 2006).

In this study, ARISA profiles were assumed to be indicative of bacterial community composition, and differences in ARISA profiles were assumed to reflect variation in the composition of the respective bacterial communities. Although this technique lacks resolution and can bias the identification of potentially important groups across the environment, the data collected allowed us to map the co-occurrence of microbial groups within two distinct environments separated by more than $3,700 \mathrm{~km}$ 
and presenting distinct vegetation cover and climate. On the other hand, examples of bacterial endemism have been found among many research studies. Fulthorpe et al. (1998) found regional endemisim of 3-chlorwobenzoate degrading soil bacteria sampled from six geographic regions at the level of REP genotype (whole genome fingerprinting), but not at the ARDRA (16S rRNA) level. Cho \& Tiedje (2000) used the same soil collection to isolate widely dispersed fluorescent Pseudomonads, and also found no geographic pattern at the ARDRA level, some at the ITS level, but strong endemicity at BOX genotype level. More recently, Wawrik et al. (2007) demonstrated the distinctiveness of New Jersey versus Uzbekistan actinomycete populations by looking at their polyketide synthase (PKS) genes.

These studies demonstrate that geographic location and environmental conditions exert strong selection pressure on species composition. However the Taxonomic units found in our work were not extant and ubiquitous; at least $40 \%$ of them were in fact present in the 21 samples tested.

\section{Conclusions}

Geographical patters in bacterial community structure were detected at broad-spectrum (between samples from different geographic locations) and specific-spectrum (within samples from different geographic locations), suggesting that microbial communities exhibit biogeographic patterns at different scales and that, at least, some taxonomic units have a wide distribution. These preliminary results support the idea that "everything is everywhere, but, the environment selects". Larger sampling and more powerful approaches would help to resolve the biases in studies involving molecular methods to determine the diversity of microorganisms and better understand the importance of the environmental and spatial factors in driving the composition of microbial communities.

\section{Acknowledgements}

This work was supported by the Fundação de Amparo a Pesquisa do Estado do Rio Grande do Sul - FAPERGS (grant number 0901855) and the Instituto Nacional de Ciência e Tecnologia Antártico de Pesquisas Ambientais - INCT-APA (CNPq process no. 574018/2008-5, FAPERJ E-26/170.023/2008, the Ministry of Science and Technology, and the secretariat for the Marine Resources Interministerial Committee (SECIRM). LFW Roesch and LN Lemos receive research fellowships from the $\mathrm{CNPq}$ (process number 503370/2009-6).

\section{References}

Cho, J.C. \& Tiedje, J.M. (2000). Biogeography and degree of endemicity of fluorescent Pseudomonas strains in soil. Applied and Environmental Microbiology, 66(12): 5448-56.

Chow, M.L.; Radomski, C.C.; McDermott, J.M.; Davies, J. \& Axelrood, P.E. (2002). Molecular characterization of bacterial diversity in Lodgepole pine (Pinus contorta) rhizosphere soils from British Columbia forest soils differing in disturbance and geographic source. FEMS Microbiology Ecology, 42(3): 347-357, 2002.

de Wit, R. \& Bouvier, T. (2006). 'Everything is everywhere, but, the environment selects'; what did Baas Becking and Beijerinck really say? Environmental Microbiology, 8(4): 755-8.

Fisher, M.M. \& Triplett, E.W. (1999). Automated approach for ribosomal intergenic spacer analysis of microbial diversity and its application to freshwater bacterial communities. Applied and Environmental Microbiology, 65(10): 4630-36.

Fulthorpe, R.R.; Rhodes, A.N. \& Tiedje, J.M. (1998). High levels of endemicity of 3-chlorobenzoate-degrading soil bacteria. Applied and Environmental Microbiology, 64(5): 1620-27.

Hackl, E.; Zechmeister-Boltenstern, S.; Bodrossy, L. \& Sessitsch, A. (2004). Comparison of diversities and compositions of bacterial populations inhabiting natural forest soils. Applied and Environmental Microbiology, 70(9): 5057-65. 
Lamarche, J.; Bradley, R.L.; Hooper, E.; Shipley, B.; Beaunoir, A.M.S. \& Beaulieu, C. (2007). Forest floor bacterial community composition and catabolic profiles in relation to landscape features in Quebec's Southern Boreal Forest. Microbial Ecology, 54(1): 10-20.

Lomolino, M.V.; Riddle, B.R. \& Brown, J.H. (2006). Biogeography. Third edition. Sinauer Associates.

Martiny, J.B.H.; Bohannan, B.J.M.; Brown, J.H.; Colwell, R.K.; Fuhrman, J.A.; Green, J.L.; Horner-Devine, M.C.; Kane, M.; Krumins, J.A.; Kuske, C.R.; Morin, P.J.; Naeem, S.; Ovreas, L.; Reysenbach, A.L.; Smith, V.H. \& Staley, J.T. (2006). Microbial biogeography: putting microorganisms on the map. Nature Reviews Microbiology, 4: 102-12.

McGrady-Steed J.; Harris, P.M. \& Morin, P.J. (1997). Biodiversity regulates ecosystem predictability. Nature, 390: 162-5.

Ranjard, L.; Poly, F.; Lata, J.-C.; Mougel, C.; Thioulouse, J. \& Nazaret, S. (2001). Characterization of bacterial and fungal soil communities by automated ribosomal intergenic spacer analysis fingerprints: Biological and methodological variability. Applied and Environmental Microbiology, 67(10): 4479-87.

Wawrik, B.; Kudiev, D.; Abdivasievna, U.A.; Kukor, J.J.; Zystra, G.J. \& Kerkhof, L. (2007). Biogeography of actinomycete communities and type II polyketide synthase genes in soils collected in New Jersey and Central Asia. Applied and Environmental Microbiology, 73(9): 2982-9.

Yergeau, E.; Bezemer, T.M.; Hedlund, K.; Mortimer, S.R.; Kowalchuk, G.A. \& Van Der Putten, W.H. (2010). Influences of space, soil, nematodes and plants on microbial community composition of chalk grassland soils. Environmental Microbiology, 12: 2096-106. 